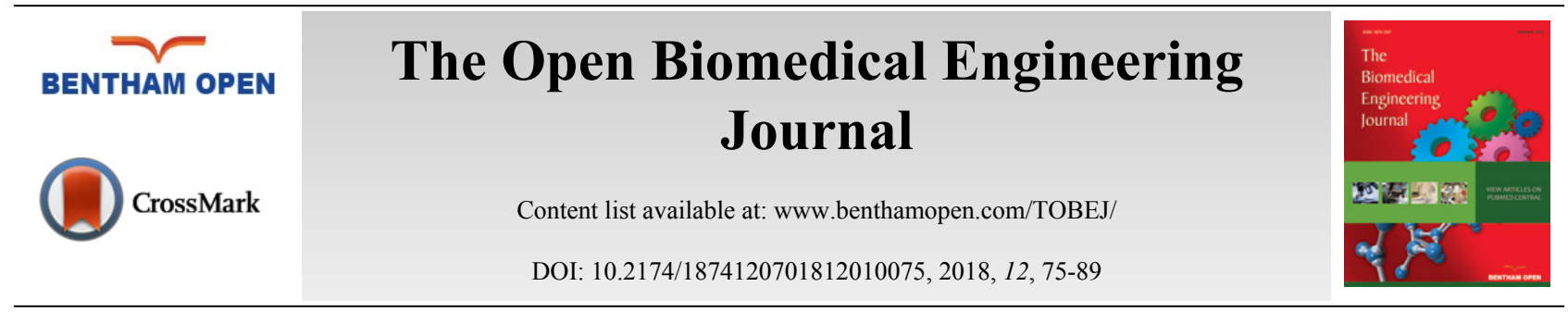

RESEARCH ARTICLE

\title{
Characterization of the F-box Proteins FBXW2 and FBXL14 in the Initiation of Bone Regeneration in Transplants given to Nude Mice
}

\author{
Mari Akiyama* \\ Department of Biomaterials, Osaka Dental University, Osaka 573-1121, Japan
}

Received: August 22, 2018

Revised: October 1, 2018

Accepted: October 2, 2018

\begin{abstract}
:
Background:

Cultured bovine-periosteum-derived cells can form three-dimensional structures on tissue culture dishes without artificial scaffolding material, can induce bone regeneration in vivo. The utility of cultured bovine-periosteum-derived cells for bone tissue regeneration after their transplantation into nude mice has been reported, the precise F-box molecular mechanism was unclear.
\end{abstract}

\section{Objective:}

The aim of this study was to investigate the specific F-box proteins required for bone regeneration by cultured bovine-periosteumderived cells in vitro.

\section{Methods:}

In the present study, periosteum tissue and cultured periosteum-derived cells were cultured for 5 weeks in vitro and then embedded in collagen gel with a green tissue-marking dye. Electrophoresis and immunohistochemistry were used to identify the specific F-box proteins required for tissue bone regeneration.

\section{Results:}

The bovine-periosteum-derived cells were observed to form bone shortly after the expression of F-box proteins. After the initial phase of bone formation, the expression of the F-box proteins ceased. FBXW2 was shown to be expressed in the periosteum, but not in cultured periosteum-derived cells. Furthermore, FBXL14 disappeared during bone formation.

\section{Conclusions:}

Bone regeneration requires progenitor cells, such as bovine-periosteum-derived cells and the activation of the F-box Proteins FBXW2 and FBXL14, over time the expression of these proteins ceases. Further scientific and clinical trials are needed to investigate how the F-box Proteins can be used therapeutically to treat osteoporosis and osteonecrosis.

Keywords: Cultured bovine-periosteum-derived cells, FBXW2, FBXL14, Bone regeneration, Osteocalcin, TRAP staining.

\section{INTRODUCTION}

The periosteum is a membrane that surrounds bones and is important in bone regeneration $[1,2]$. It consists of a fibrous outer layer and an inner cambium layer that continuously generates osteoblasts, causing bone growth [3]. The periosteum contains osteoblasts, fibroblasts that are indistinguishable from the adjacent osteoblasts, multipotent cells that can differentiate into osteoblasts, and chondrocyte [3 - 5]. The periosteum has a different ultrastructure and osteogenic potential according to its location [6]. For instance, the calvarial periosteum has less osteogenic potential

\footnotetext{
* Address correspondence to this author at the Department of Biomaterials, Osaka Dental University, 8-1 Kuzuhahanazono-cho, Hirakata, Osaka 573-1121, Japan; Tel: +81 72864 3056; Fax: +81 72864 3156; E-mail: mari@cc.osaka-dent.ac.jp
} 
than the tibial periosteum, as described by Dwek [3]. The osteoblastic differentiation and bone regeneration potential of periosteum-derived cells, which are a mixture of multipotent cells and fibroblasts, have been studied [6 - 9]. For example, cultured bovine-periosteum-derived cells can form three-dimensional multiple-cell-layered structures on tissue culture dishes without artificial scaffolding material, and can subsequently be used for bone regeneration in vivo $[10,11]$. Despite advances in the use of cultured bovine-periosteum-derived cells for bone tissue regeneration after their transplantation into nude mice, the precise mechanism of bone formation remains unclear. Specifically, it is unclear which proteins are required to form the multicellular layer that is necessary to initiate bone regeneration.

Previous studies have identified some of the proteins that are expressed by cultured periosteum-derived cells. For example, using Mass Spectrometry (MS) and Immunohistochemistry (IHC), Akiyama [12, 13] recently reported that uveal autoantigen with coiled-coil domains and ankyrin repeats (UACA), exosome complex component RRP45 (EXOSC9), thioredoxin-related transmembrane protein 2 (TMX2), beta-tubulin, and F-box/leucine-rich repeat protein 14 (FBXL14) are expressed in cultured bovine-periosteum-derived cells. Another study identified candidate proteins present in cultured bovine-periosteum-derived cells using MS. However, only small peptide fragments were detected, making their identification difficult. Some of the proteins were confirmed with IHC in paraffin sections of cultured bovine-periosteum-derived cells using antibodies directed against each candidate protein [12, 13]. However, some proteins in these cells could not be confirmed [12].

One of the candidate proteins detected with MS that is not expressed in the multilayer of cultured bovineperiosteum-derived cells is the F-box protein F-box/WD repeat-containing protein 2 (FBXW2). However, the F-box protein FBXL14 was identified with IHC. The F-box proteins are divided into three classes: FBXW, defined by a WD repeat motif; FBXL, defined by a leucine-rich repeat motif; and FBXO, which includes proteins with an F-box and either another or no other binding motif [14]. F-box proteins recognize E3 ubiquitin ligases, but other roles, beyond ubiquitination, have also recently been reported [15 - 17]. FBXW11, FBXL1, and FBXW7 are the three bestcharacterized of the 69 F-box proteins $[18,19]$ and FBXW7 is particularly well characterized in tumors [17]. FBXW2 is reported to regulate placental cell migration and invasion [20,21], but its roles in the periosteum and bone regeneration are still unclear. In a previous study, the original periosteum was removed from primary cultured cells and only the bulk of the cultured periosteum-derived cells was investigated $[12,13]$. Cultured periosteum-derived cells and periosteum were examined in parallel in that study, and FBXW2 was found to be expressed in the periosteum but not in the cultured periosteum-derived cells.

Several more factors present in the periosteum have been identified. For example, a recent review by Lin et al. [22] described the interactions between bone morphogenetic protein, fibroblast growth factor, Hedgehog, Notch, plateletderived growth factor, WNT, and inflammation signaling during bone regeneration [22]. Cherry et al. [23] also demonstrated that the periosteum displays properties of mesenchymal stromal/stem cells, although equivalent cells were not identified in the periosteum because no specific markers were available. Two osteogenic markers, osteocalcin (for osteoblasts) and Tartrate-Resistant Acid Phosphatase (TRAP; for osteoclasts), are known [24, 25]. Although significant research into the proteins related to bone formation, including osteocalcin and TRAP, has been conducted, the interaction between FBXW2 and the periosteum has not been investigated. Therefore, the aim of this study was to investigate the specific F-box proteins required for bone regeneration by cultured bovine-periosteum-derived cells in vitro.

\section{MATERIALS AND METHODS}

\subsection{Cell Culture}

All animal experiments were performed according to the guidelines for animal experimentation of Osaka Dental University (no. 15-01007). Bovine periosteum from the legs of Japanese black cattle was used for explant culture for 5 weeks in medium 199 containing ascorbic acid, as described previously [10]. The Japanese black cattle were 30-monthold adult steers (ex-male) or cows obtained from a slaughterhouse (Kobe Chuo Chikusan, Kobe, Japan) preparing meat products. Twenty-four hours after the death of the animal, the bovine periosteum was used for cell culture, according to the guidelines for animal experimentation at Osaka Dental University (no. 15-01007). Two pieces of periosteum tissue $\left(5 \times 5 \mathrm{~mm}^{2}\right)$ were placed on 100 -mm dishes for 5 weeks. It has previously been reported that bone was successfully regenerated in culture medium containing ascorbic acid, whereas medium without ascorbic acid bone did not allow this regeneration [11]. Therefore, in this study, all experiments were performed with ascorbic acid, and the culture medium was changed once a week. For MS, the medium was changed to medium without Fetal Bovine Serum (FBS) after 4 
weeks, and the cells were cultured for 1 week in the FBS-free medium. The supernatants without FBS were collected.

\subsection{MS and Selection of FBXW2}

As in previous studies, the supernatant samples from cultured periosteum-derived cells were subjected to twodimensional electrophoresis [12,13]. When the cells were cultured in the presence of ascorbic acid, spots containing type 1 collagen and noncollagenous proteins were observed, and those spots were analyzed with MS/MS using Micro $T O F-Q$ mass spectrometer (BrukerDaltonics, Bremen, Germany) [12, 13]. Details of the search parameters and the results of a MASCOT search [26] are shown in Table 1. As shown in Fig. (1 and Table 1), FBXW2 was identified as a candidate protein in this study.

Table 1. Search parameters and the results of a MASCOT search for candidate protein FBXW2. Segments of the FBXW2 peptides detected in the supernatants of cultured bovine-periosteum-derived cells were matched.

\begin{tabular}{|l|l|}
\hline Entry Name & FBXW2_BOVIN \\
\hline Accession Number & Q58D00; Q58DP3 \\
\hline Full Name & F-box and WD-40 domain-containing protein 2 \\
\hline Database & SwissProt \\
\hline Enzyme & Trypsin \\
\hline Taxonomy & Other mammalia \\
\hline Variable Modifications & Carbamidomethyl (C), Oxidation (M) \\
\hline Peptide Mass Tolerance & $50 \mathrm{ppm}$ \\
\hline Fragment Mass Tolerance & 0.1 Da \\
\hline Amino Acid Sequence & $71-85:$ K.WLDPQTLLTCCLVSK.Q \\
\hline Protein Sequence Coverage & $3 \%$ \\
\hline
\end{tabular}

Supernatant of cultured bovineperiosteum-derived cells
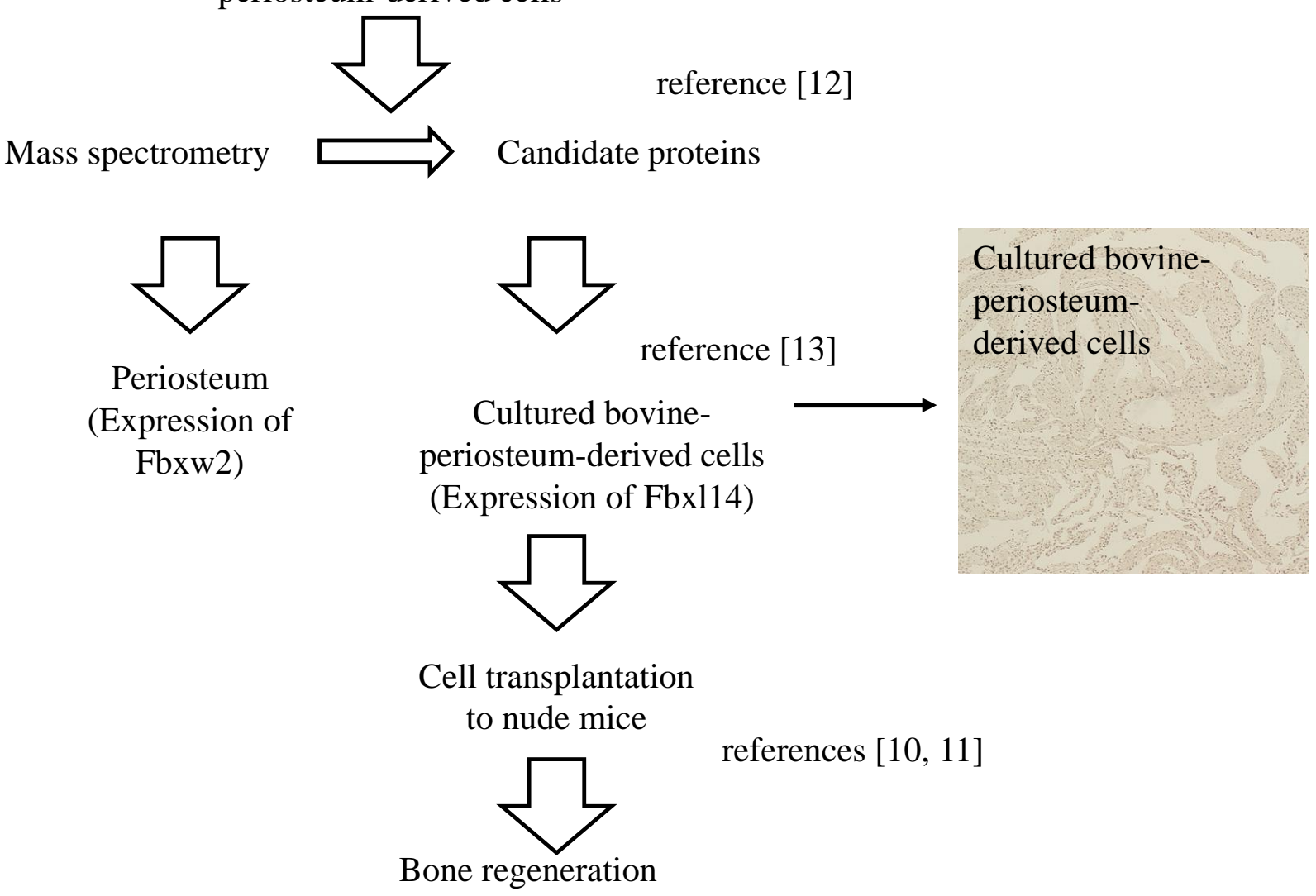

Fig. (1). Outline of this study. A combination of MS and IHC identified periosteal-specific proteins. Periosteum, periosteal cells, cultured bovine-periosteum-derived cells, and new bone tissue generated with cell transplantation were examined. 


\subsection{Cross-sections of Periosteum and Cultured Periosteum-derived Cells}

The methods used to produce cross-sections of the periosteum and cultured periosteum-derived cells are described in Fig. (2). After 5 weeks, both the periosteum and cultured periosteum-derived cells were removed from the tissue culture dishes and embedded in collagen gel (Cellmatrix Type1-A, Nitta Gelatin, Osaka, Japan), marked with a green tissue marker (Tissue Marking Dye, Falma Co. Ltd, Tokyo, Japan) on top, which indicated the upper sides of the culture dishes. These cell mixtures were fixed in $4 \%$ paraformaldehyde (PFA), and the paraffin blocks were sectioned to $6 \mu \mathrm{m}$. The paraffin sections were then prepared for IHC.

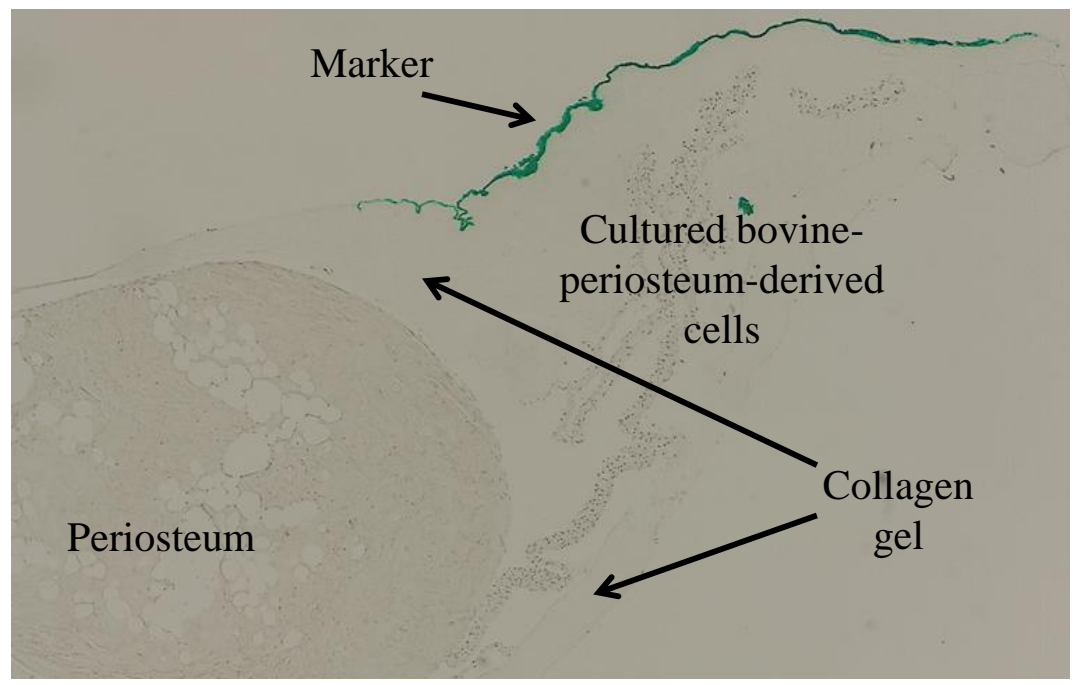

Fig. (2). Outline of a cross-section of the periosteum and cultured bovine-periosteum-derived cells in collagen gel.

\subsection{Immunohistochemistry}

In previous studies, peptide fragments of UACA, EXOSC9, TMX2, beta-tubulin, and FBXL14 were detected, with protein sequence coverages of approximately $1 \%, 3 \%, 3 \%, 2 \%$, and $3 \%$ for each protein, respectively [12, 13]. Therefore, each protein was confirmed with IHC, as described in the previous studies [12, 13].

The paraffin sections were pretreated with proteinase K (Dako Cytomation, Glostrup. Denmark) and a peroxidase blocking solution (Dako). Two primary antibodies directed against F-box proteins and an antibody directed against osteocalcin were used: anti-FbxW2 antibody (ab5309; Abcam, Cambridge, UK), anti-FBXL14 antibody (SAB2103691-50UG, Sigma-Aldrich Co., St. Louis, MO), and anti-osteocalcin (code no. M042, clone no. OCG2; Takara Bio Inc., Otsu, Japan). Three secondary antibodies were used: horseradish peroxidase (HRP)-labeled anti-goat immunoglobulin (P0449, Dako) for the anti-FbxW2 antibody; Envision+ System HRP-labeled polymer anti-rabbit immunoglobulin (Dako) for the anti-FBXL14 antibody; and the Envision+ System HRP-labeled polymer anti-mouse immunoglobulin (Dako) for the anti-osteocalcin antibody. The anti-FbxW2 antibody was diluted 1:100 and applied to the sections for $2 \mathrm{~h}$; the anti-FBXL14 antibody was diluted to $0.33 \mu \mathrm{g} / \mathrm{ml}$ and applied for $1 \mathrm{~h}$; and the anti-osteocalcin antibody was diluted 1:500 and applied for $4 \mathrm{~h}$. Anti-goat immunoglobulin-HRP was diluted to 1:100 and the Envision solutions were not diluted. Hematoxylin was used to counterstain the nuclei. Independent experiments were repeated three times.

\subsection{Cell Transplantation and Bone Regeneration}

Prior to surgery the animals were given general anesthesia and their vital signs were monitored. The cell transplantation process is shown in Fig. (1). which is similar to previous studies [10,11]. After 5 weeks in culture in vitro, the periosteum-derived cells was excised and transplanted into the back skin of three male nude KSN mice (6 weeks old; Shimizu Laboratory Supplies Co., Ltd). Cultured periosteum-derived cells were separated from six pieces of periosteum. Cells embedded in extracellular matrix, such as collagen fibers, were not trypsinized or counted. After 4 weeks, the mice were euthanized with an overdose of isoflurane. The skin from the nude mice and the new bone tissue from the cultured periosteum-derived cells were fixed in 4\% PFA. Paraffin sections were prepared for IHC and Hematoxylin and Eosin (HE), von Kossa, and TRAP staining. 


\section{RESULTS}

Immunohistochemistry (IHC) was used to determine whether the F-box proteins FBWX2 and FBXL14 were expressed in cultured periosteum-derived cells. Table 2 summarizes the results of IHC in this study. FBXW2 was expressed in the periosteum, whereas FBXL14 was expressed in the cultured periosteum-derived cells, and osteocalcin was expressed in both the cultured periosteum-derived cells and the transplanted cells.

Table 2. Summary of the immunohistochemical analysis of FBXW2, FBXL14, and osteocalcin.

\begin{tabular}{|l|c|c|c|c|}
\hline & Periosteum & $\begin{array}{c}\text { Periosteal cells (in } \\
\text { periosteum) }\end{array}$ & $\begin{array}{c}\text { Cultured periosteum-derived cells (outside } \\
\text { the periosteum) }\end{array}$ & $\begin{array}{c}\text { Transplanted cultured periosteum- } \\
\text { derived cells }\end{array}$ \\
\hline FBXW2 & $\circ$ & $\times$ & $\times$ & $\times$ \\
\hline FBX114 & $\times$ & $\circ$ & $\circ$ & $\times$ \\
\hline Osteocalcin & $\times$ & $\circ$ & $\circ$ & $\circ$ \\
\hline
\end{tabular}

FBXW2 was expressed in the periosteum, but not in the cultured periosteum-derived cells or transplanted cells (Fig. 3A-C). Although FBXW2 was identified as a putative component of proteins secreted from the cultured periosteumderived cells with MS, IHC was unable to confirm this finding in previous studies, presumably because FBXW2 was only present in the periosteum (Fig. 3A, B). Consistent with this, the transplanted cells were also negative for FBXW2 (Fig. 3C).

A

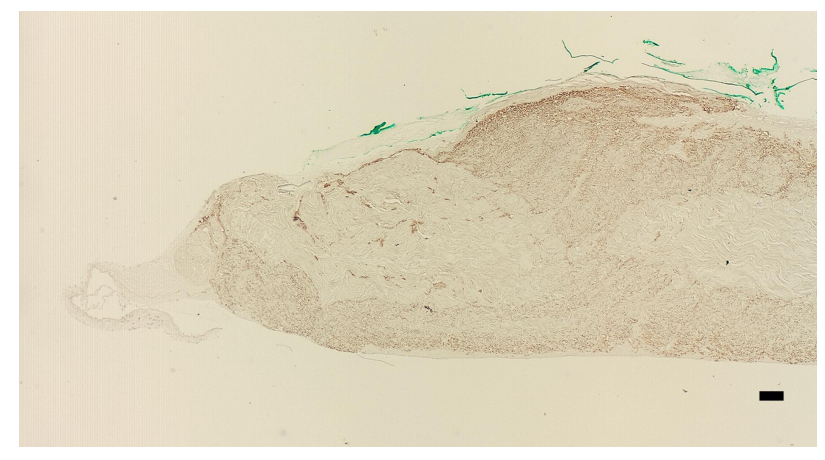

$\mathrm{B}$

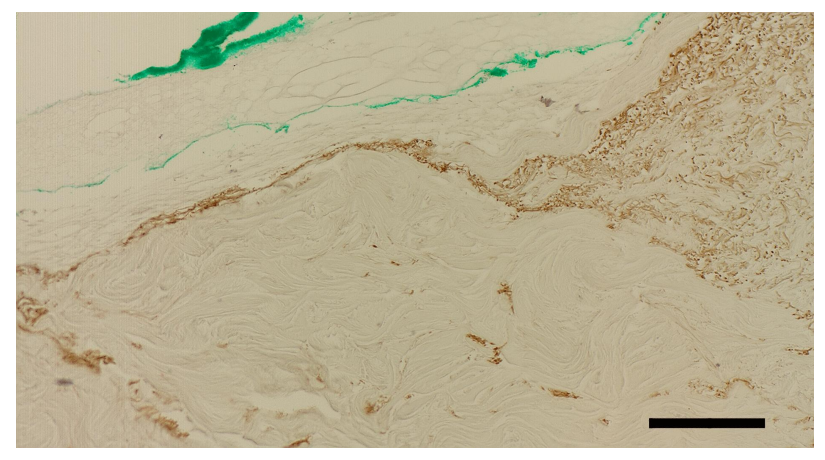

C

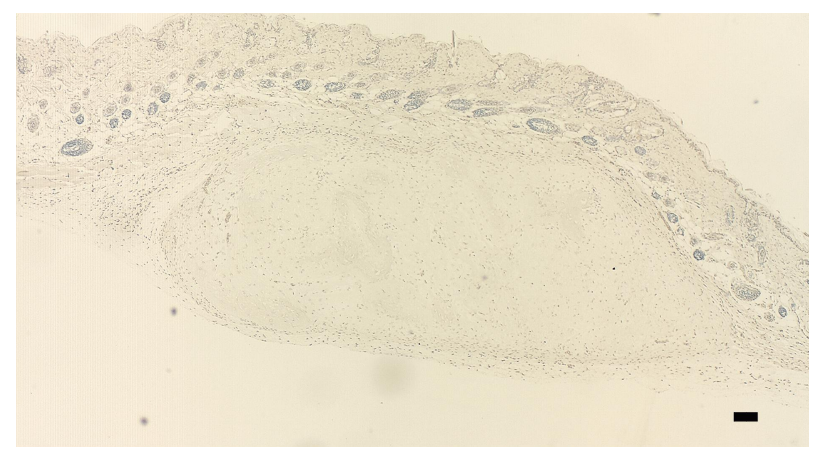

Fig. (3). IHC of FBXW2. (A) Five weeks after explant culture of bovine periosteum. (B) High-power field of (A). (C) After cell transplantation into nude mouse skin and the formation of new bone tissue. Scale bars: $100 \mu \mathrm{m}$. 
In contrast, FBXL14 was not expressed in the periosteum, but in the periosteal cells located within the periosteum and in the cultured periosteum-derived cells (Fig. 4A, B). Surprisingly, although FBXL14 was present in the cultured periosteum-derived cells before transplantation, the transplanted cells were negative for FBXL14 (Fig. 4C). In vivo, that part of the skin surface of the nude mice was positive for FBXL14 (Fig. 4C).
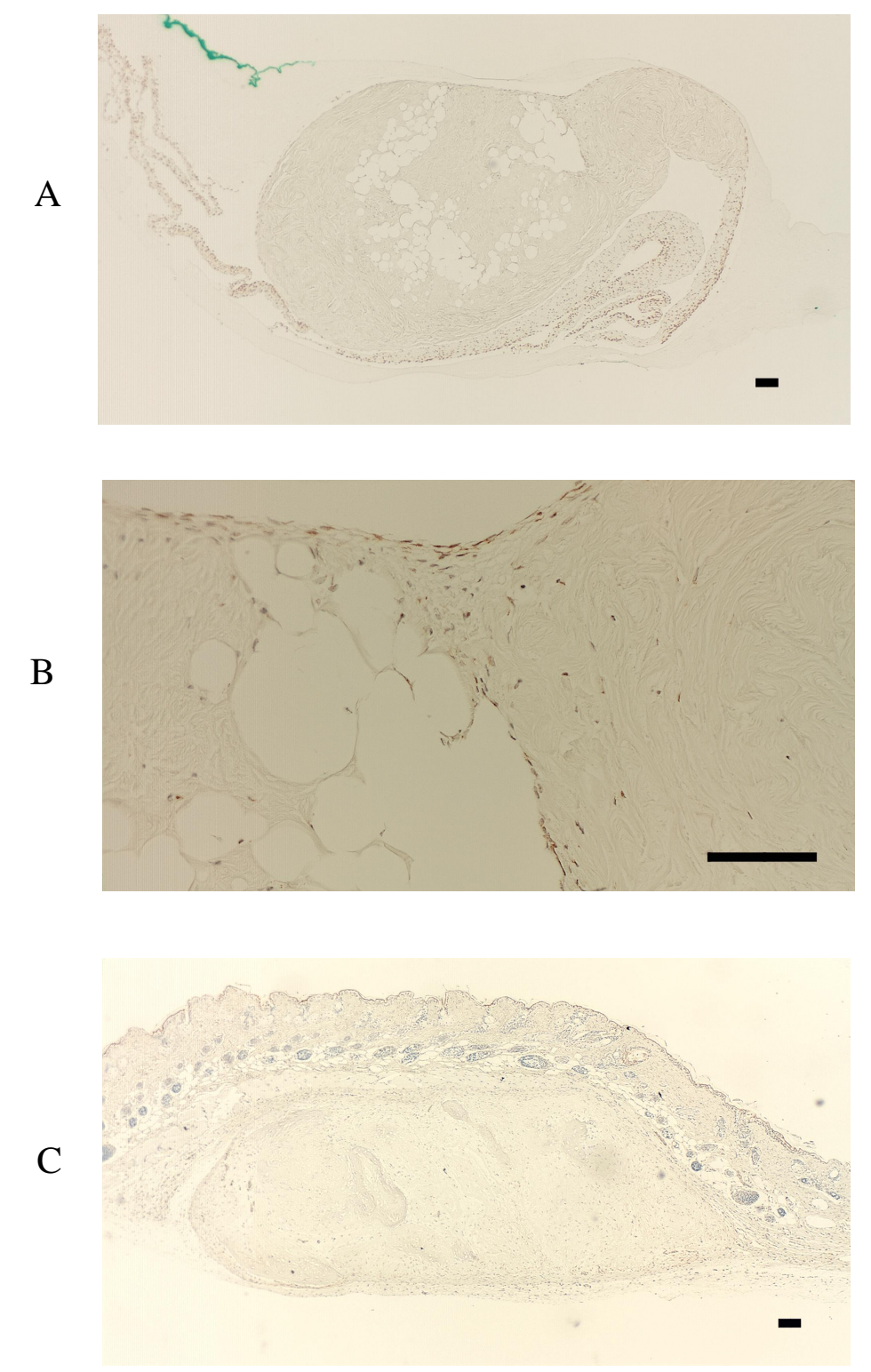

Fig. (4). IHC of FBXL14. (A) Five weeks after explant culture of bovine-periosteum-derived cells. (B) High-power field of (A). (C) After cell transplantation into nude mouse skin and the formation of new bone tissue. Scale bars: $100 \mu \mathrm{m}$.

To localize the F-box proteins FBXW2 and FBXL14 during the process of new bone formation, sections were analyzed 4 weeks after transplantation with HE staining, von Kossa staining, the immunohistochemical detection of osteocalcin, and TRAP staining. It has previously been reported that posttransplantation bone regeneration is completed within 6 weeks [10]. Consistent with this, there was evidence of bone formation at 4 weeks in this study, apparent as partially calcified new bone tissue (Fig. 5A-D). However, at this stage, it was clear that the expression of FBXW2 and FBXL14 had ceased during bone development. 
A

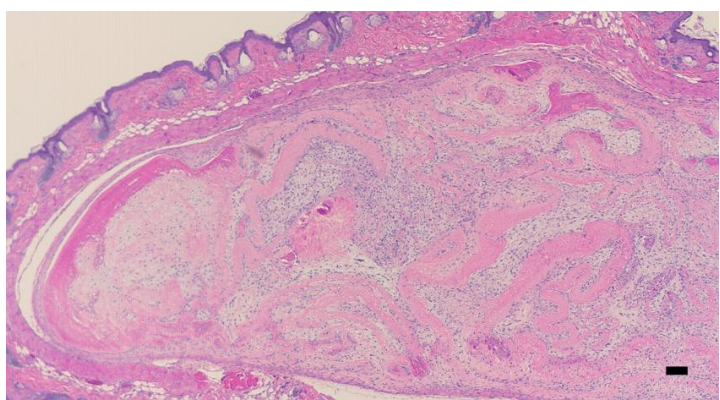

B

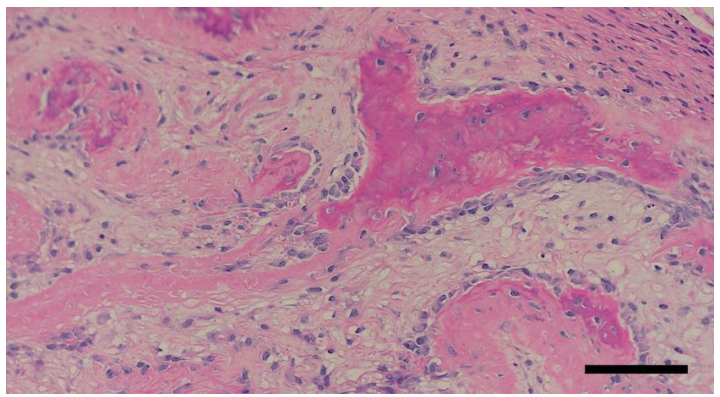

$\mathrm{C}$

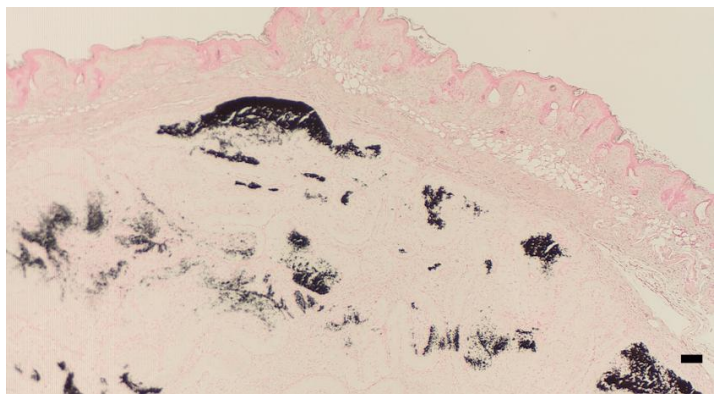

D

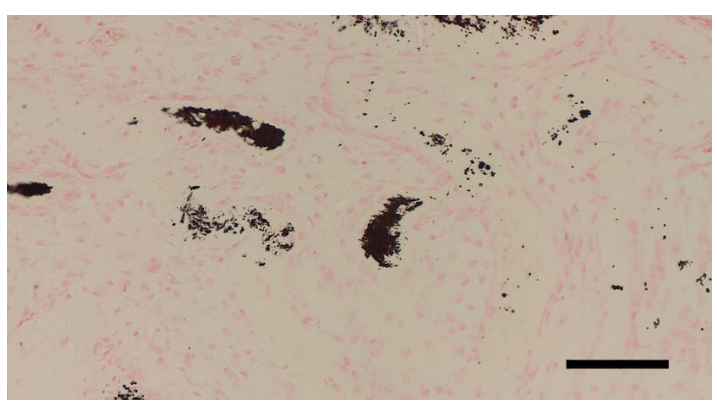

Fig. (5). Transplanted bovine-periosteum-derived cells. (A) HE staining. (B) High-power field of (A). (C) von Kossa staining. (D) High-power field of (C). Scale bars: $100 \mu \mathrm{m}$.

Osteocalcin was also present in the cultured bovine-periosteum-derived cells and transplanted cells (Fig. 6A-D). However, only one side of the periosteum-derived cell layer was positive for FBXL14, whereas both sides of cell layer were positive for osteocalcin (Fig. 6A, B). Specifically, at 4 weeks posttransplantation, cultured periosteum-derived cells expressing osteocalcin were observed around the new bone tissue and future bone tissue (Fig. 6C, D). In the HEstained samples in Fig. (5A, B), the new bone tissue stained strongly pink and osteoblasts were present around the bone tissue. Therefore, the osteocalcin-positive cells in Fig. (6C, D) appear to be osteoblasts. The results shown in Fig. (6C, D) also indicate that the cultured bovine-periosteum-derived cells were positive for osteocalcin before transplantation (Fig. 6A, B). Areas near the new bone tissue were also positive for TRAP staining, a marker of osteoclasts (Fig. 7A, B). 

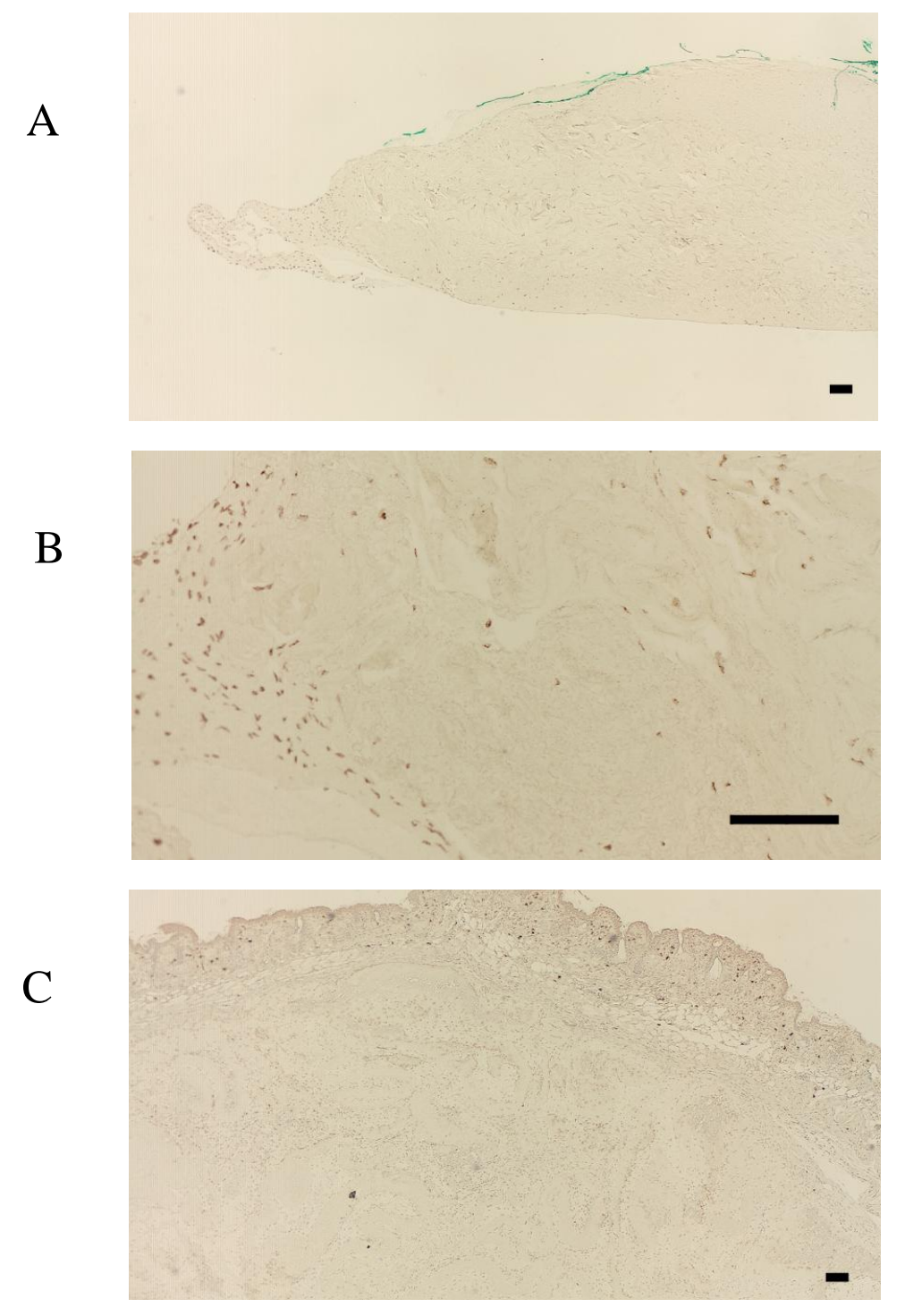

D

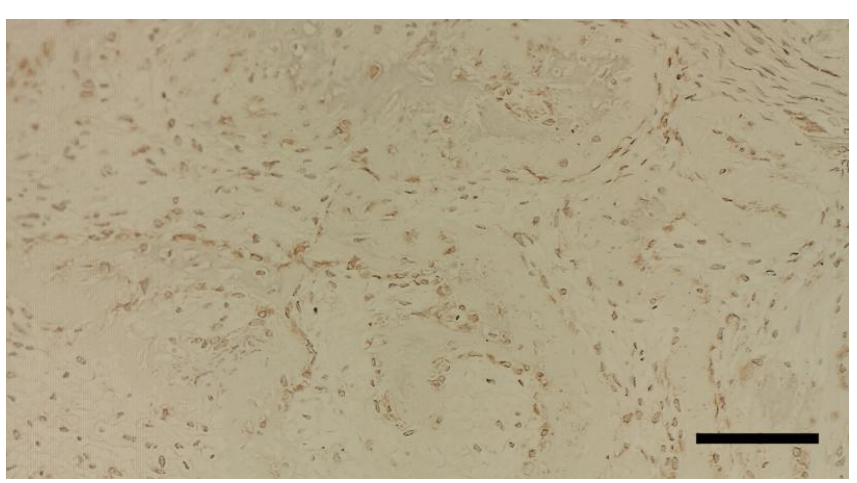

Fig. (6). IHC of osteocalcin. (A) Five weeks after explant culture of bovine-periosteum-derived cells. (B) High-power field of (A). (C) After cell transplantation into nude mouse skin and the formation of new bone tissue. (D) High-power field of (C). Scale bars: $100 \mu \mathrm{m}$. 

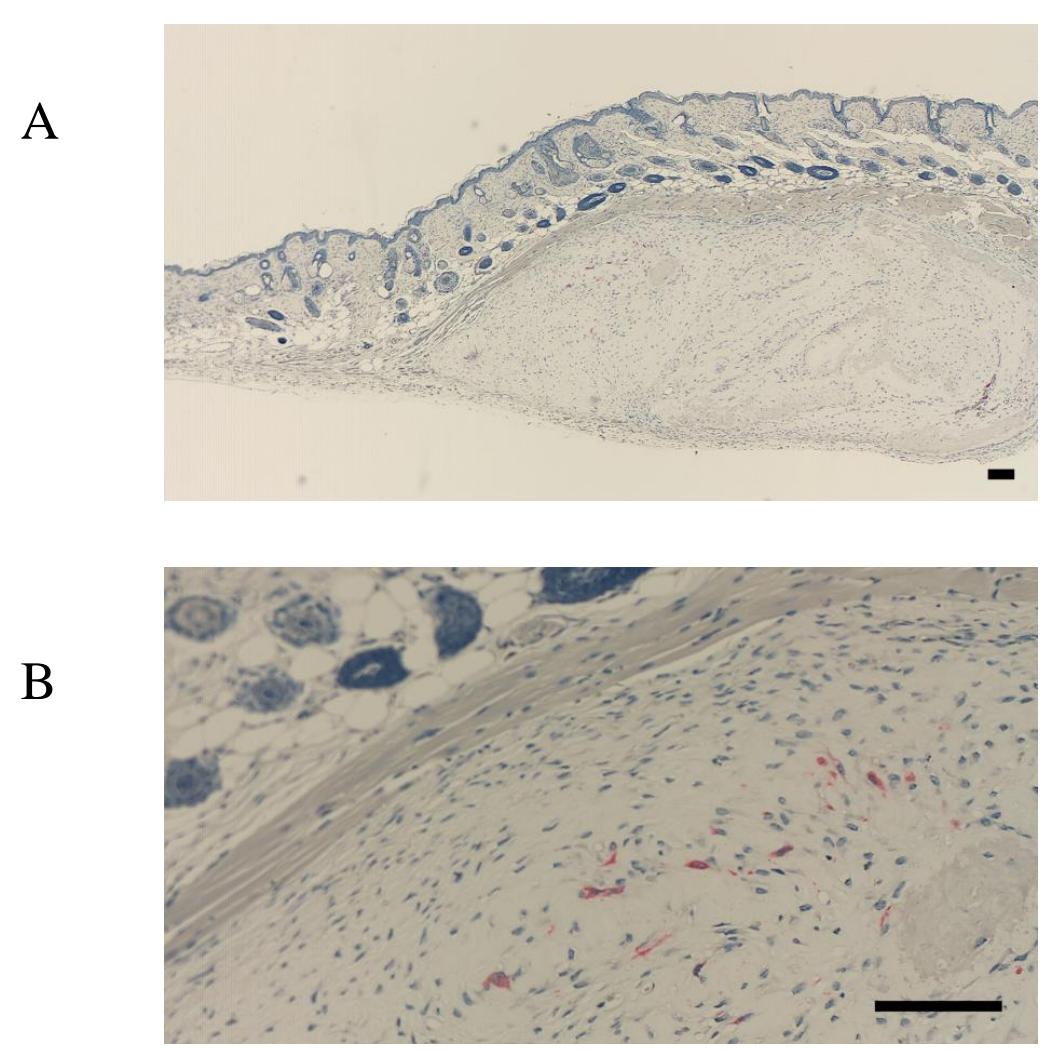

Fig. (7). TRAP staining. (A) After cell transplantation into nude mouse skin and the formation of new bone tissue. (B) High-power field of (A). Scale bars: $100 \mu \mathrm{m}$.

\section{DISCUSSION}

The results of this present study are the first to demonstrate that the F-box Proteins FBXW2 and FBXL14 are involved in the initiation of bone regeneration. The results offer the potential to use F-box proteins therapeutically to regenerate bone where bone loss has occurred through diseases involving macrophage activity such as osteoporosis and osteonectrosis, and as coatings on orthopedic and tooth implants to promote healing.

However, the F-box proteins have not been reported to be associated with the periosteum or periosteum-derived cells. The present results explain this phenomenon by showing that the F-box proteins, such as FBXW2 and FBXL14, are present during the initiation phase of cell layer development, but are then lost during bone regeneration.

Recently, using MS and a MASCOT analysis, Akiyama [13] reported that one of the F-box proteins, FBXL14, is present in cultured bovine-periosteum-derived cells. However, an antibody directed against another candidate protein, FBXW2, did not react, or reacted extremely weakly, with bulk sections of cultured bovine-periosteum-derived cells lacking periosteum. This indicates that FBXW2 is present in the periosteum and FBXL14 is present in cultured periosteum-derived cells.

In previous studies, some candidate proteins identified with MS were not detected in subsequent confirmatory experiments, which suggests that those proteins are also only present in the periosteum. Mass spectrometry is an imperfect technique, and sometimes detects false-positive proteins. Therefore, Akiyama [12] combined MS with IHC in that study. In the present study, MS identified proteins not only in the cultured periosteum-derived cells, but also in the periosteum. The utility and importance of protein detection with MS, and its confirmation with IHC, are highlighted in this study. Alternatively, western blotting analyses of the culture supernatants of cultured bovine-periosteum-derived cells have previously been used as an effective validation tool. However, western blotting requires a large volume of protein and fragments of the proteins in the supernatant cannot be detected. In contrast, IHC can detect small volumes of protein with an antibody and can be used to localize the proteins [26].

Previously, Miura et al. [27] reported that the F-box protein FWD2 is predominantly expressed in the liver and is distributed in the cytoplasm. They suggested that SKP1, CUL1, and the F-box protein FWD2 form the 'SCF' complex, 
and that this complex plays a critical role in the ubiquitin-dependent degradation of proteins expressed in the liver. Hungwen Chen's group also reported that the F-box protein FBW2 interacts with glial cell missing 1 (GCM1) and regulates the stability of GCM1 in the placenta [16, 20, 21, 28]. Similarly, Zheng et al. [29] reported that FBXL14 interacts with MKP3, which is expressed during axis formation in the zebrafish embryo. FBXL14 has also been reported to interact with and promote the ubiquitination of SNAL1, one of the SNAIL family of zinc-finger transcription factors [30]. The Human Protein Atlas website [31] presents a map of protein expression across 32 human tissues [32]. According to this map FBXW2 is strongly expressed in the small intestine and smooth muscle, whereas FBXL14 is expressed in the small intestine, endometrium, skin, tonsil, and 34 cell lines. However, the roles of FBXW2 and FBX114 in the periosteum and bone are unclear. In the present study, two F-box proteins, FBXW2 and FBXL14, were detected in different sections: FBXW2 in the periosteum, but not in the cytoplasm, and FBXL14 in cultured periosteum-derived cells. This suggests that the roles of FBXW2 and FBXL14 differ. FBXW2 is only expressed in the periosteum in the bush-like tissue outside the cells, and not in the derived cells around the periosteum. Because FBXW2 is not present in cultured bovine-periosteum-derived cells, this protein might play a role in the transportation of primary cultured cells out of the firm collagen fibers of the periosteum (Fig. 8A, B). Conversely, FBXL14 is present in the cultured cells around the periosteum. Therefore, FBXL14 might have a role in forming the cultured periosteum-derived cell layer around the periosteum and in cell migration (Fig. 8C). Neither FBXW2 nor FBXL14 was expressed during bone formation, so these proteins might be required before bone formation. In summary, FBXW2 and FBXL14 are associated with cells that potentially form bone tissue, but their expression ceases in new bone tissue. The results of the present study show the changes in the expression of these proteins during the initiation stage, before bone formation.

A

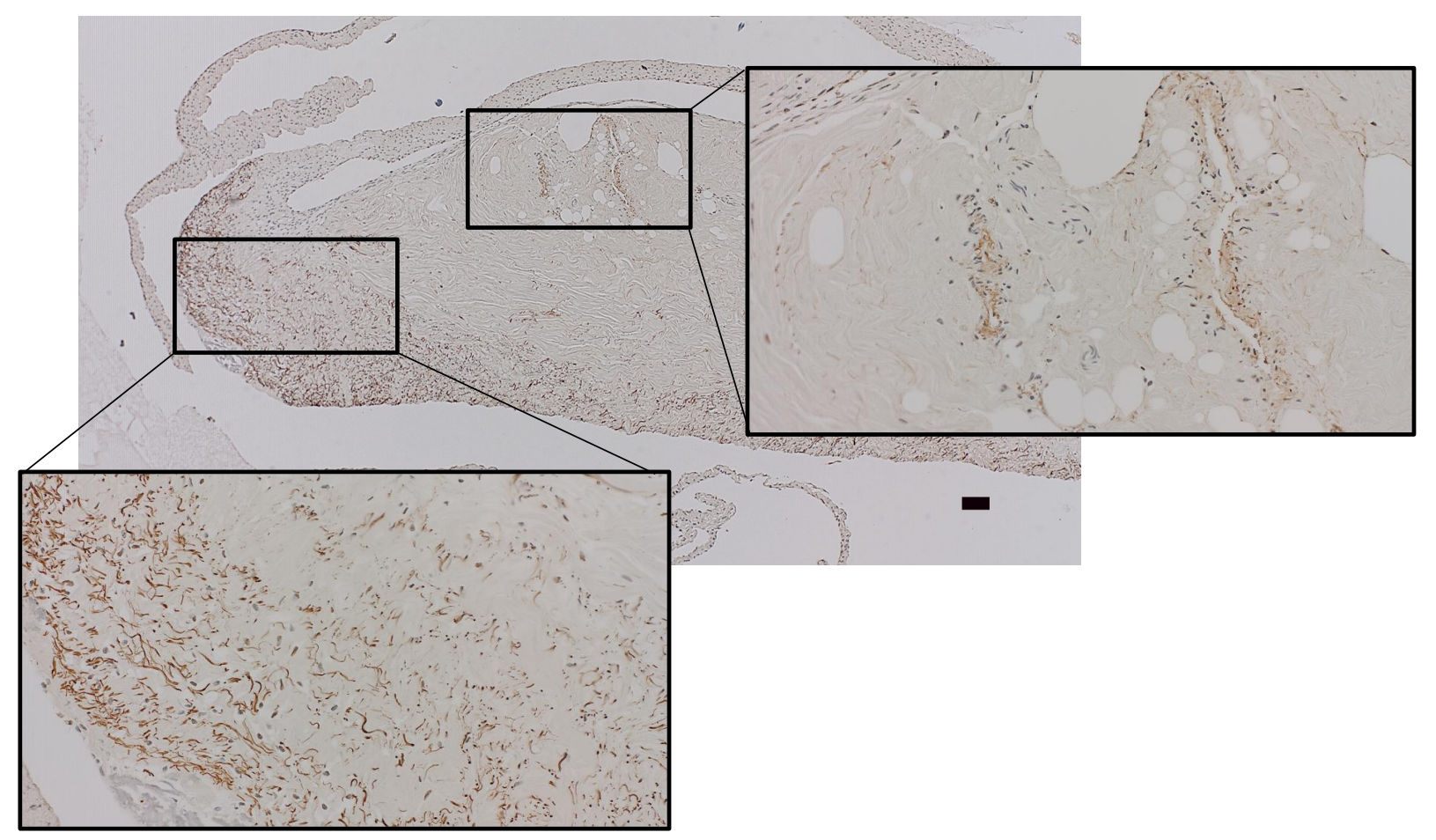


B

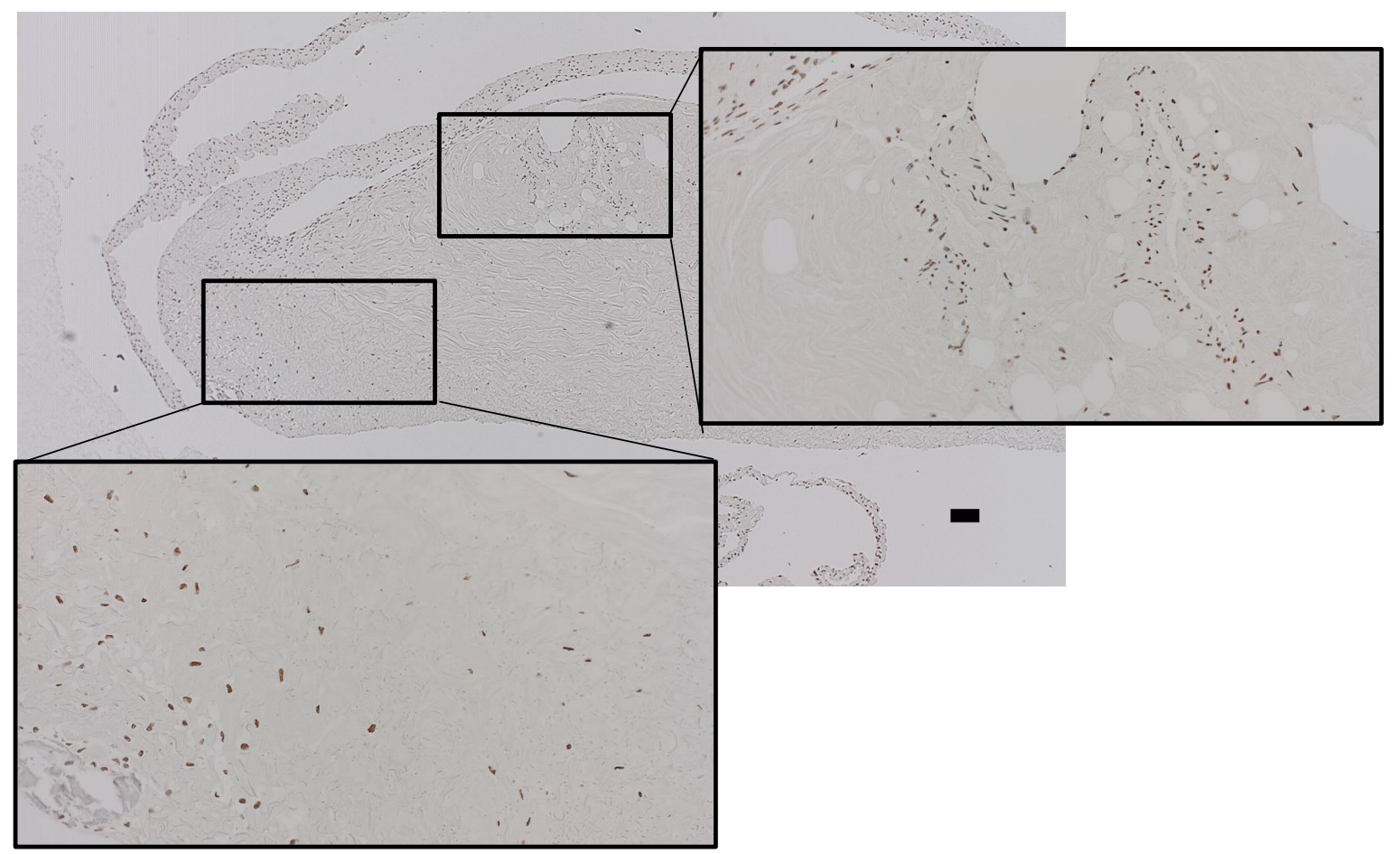

C

Step 1

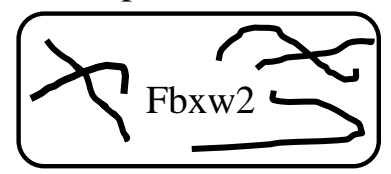

Periosteum

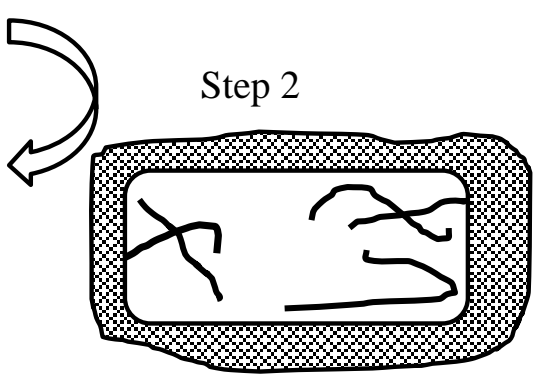

\section{Cultured bovine- \\ periosteum-derived cells}

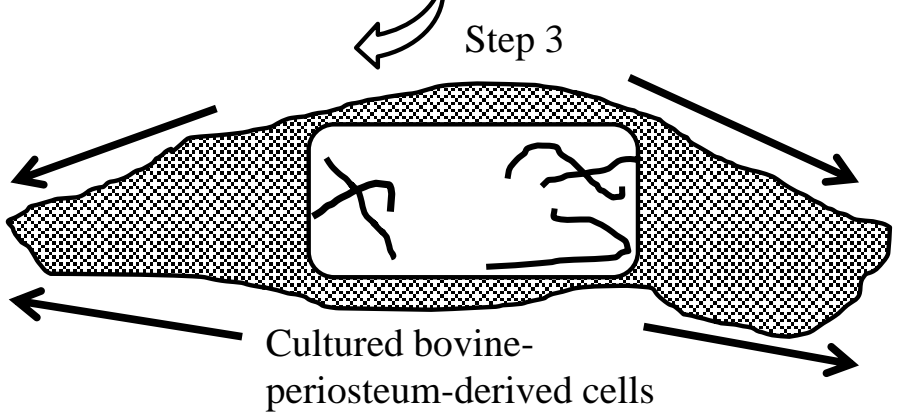

Fig. (8). Hypothetical roles of the F-box proteins determined in this study. (A, B) Immunohistochemistry of FBXW2. Five weeks after explant culture of bovine periosteum. Scale bars: $100 \mu \mathrm{m}$. (C) Two F-box proteins, FBXW2 and FBXL14, are required for cell layer formation before bone formation. 
In previous studies, cultured bovine-periosteum-derived cells regenerated bone after their transplantation into nude mice [10, 11]. For example, in 2006, Akiyama et al. [10] showed that osteocalcin was detectable with IHC 6 weeks after the transplantation of new bone tissue. In the present study, an anti-osteocalcin antibody was used as an osteoblast marker and TRAP staining was used as an osteoclast marker. HE staining and von Kossa staining revealed that osteocalcin was expressed around the new bone tissue and future bone tissue, whereas an IHC analysis of osteocalcin detected only osteoblasts in sections of transplanted cells, even though osteocalcin was strongly expressed in the study by Akiyama et al. [10]. One possible explanation for this discrepancy is that different osteocalcin antibodies targeting different regions of the protein were used in the two studies (present study: code no. M042, clone no. OCG2; previous study: code no. M041, clone no. OC4-30 [10]; Takara Bio Inc.). Different antibody dilutions were also used in the two studies. Specifically, in the present study, the osteocalcin antibody was diluted 1:500 to avoid background staining, whereas in the previous study, the antibody used was diluted 1:200 [10].

In the present study, I used cells at 4 weeks posttransplantation and a small area of new bone tissue to observe the process of bone formation (Fig. 5A). At 4 weeks posttransplantation, the presence of osteoclasts, detected with TRAP staining, was remarkable because the cultured periosteum-derived cells caused bone formation after remodeling. Some periosteum-associated proteins have been widely used as markers of bone, including alkaline phosphatase, bone GLA protein, runt-related transcription factor 2 (RUNX2), osterix, and bone morphogenetic protein [2, 33]. However, the Fbox proteins have not been reported to be associated with the periosteum or periosteum-derived cells. The present results explain this phenomenon by showing that the F-box proteins, such as FBXW2 and FBXL14, are present during the initiation phase of cell layer development, but are then lost during bone regeneration. Consistent with this, Akiyama et al. [10] demonstrated that the multiple layers of cultured bovine-periosteum-derived cells do not expand across the entire $100 \mathrm{~mm}$ of the tissue culture dishes, but expand radially for 15-20 mm around the periosteum in 100-mm tissue culture dishes containing ascorbic acid. Therefore, I hypothesize that cultured periosteum-derived cells are required to initiate the initial three-dimensional structure (Fig. 8C). The model I propose is that in Step 1, FBXW2 is expressed in the periosteum. Subsequently (Step 2), cultured periosteum-derived cells expressing FBXL14 form around the periosteum cell layer. Finally (Step 3), the layer of cultured periosteum-derived cells becomes thick and moves to both sides.

\section{CONCLUSIONS}

Bone regeneration requires progenitor cells, such as bovine-periosteum-derived cells and the activation of the F-box Proteins FBXW2 and FBXL14, over time the expression of these proteins ceases. Further scientific and clinical trials are needed to investigate how the F-box Proteins can be used therapeutically to treat osteoporosis and osteonecrosis.

\section{LIST ABBREVIATIONS}

$\begin{array}{lll}\text { UACA } & = & \text { Uveal Autoantigen with Coiled-coil domains and Ankyrin repeats } \\ \text { EXOSC9 } & = & \text { Exosome complex component RRP45 } \\ \text { TMX2 } & = & \text { Thioredoxin-related transmembrane protein } 2 \\ \text { FBXL14 } & = & \text { F-box/leucine-rich repeat protein } 14 \\ \text { F-box/WD } & = & \text { Repeat-containing protein 2 (FBXW2) } \\ \text { MS } & = & \text { Mass Spectrometry ; IHC, Immunohistochemistry } \\ \text { TRAP } & = & \text { Tartrate-Resistant Acid Phosphatase } \\ \text { FBS } & = & \text { Fetal Bovine Serum } \\ \text { PFA } & = & \text { Paraformaldehyde } \\ \text { HRP } & = & \text { Horseradish Peroxidase } \\ \text { HE } & = & \text { Hematoxylin and Eosin }\end{array}$

\section{ETHICS APPROVAL AND CONSENT TO PARTICIPATE}

All protocols were approved by Animal Research Committee of Osaka Dental University (approval number no. 15-01007). 


\section{HUMAN AND ANIMAL RIGHTS}

Humans did not participate in this research. All animal research procedures followed were in accordance with the US National Research Council's "Guide for the Care and Use of Laboratory Animals.

\section{CONSENT FOR PUBLICATION}

Not applicable.

\section{CONFLICT OF INTEREST}

The authors declare no conflict of interest, financial or otherwise.

\section{ACKNOWLEDGMENTS AND FUNDING}

This work was supported by JSPS KAKENHI grant number 26462986. The author would like to thank Kobe Chuo Chikusan for providing the bovine legs. This study was performed at the Institute of Dental Research, Osaka Dental University (Dental Bioscience Facilities). The author would like to thank Prof. Koichi Imai and Dr. Kazuya Masuno at Osaka Dental University for their helpful discussions. The author has no conflicts of interest to declare.

\section{REFERENCES}

[1] Q. Wang, C. Huang, M. Xue, and X. Zhang, "Expression of endogenous BMP-2 in periosteal progenitor cells is essential for bone healing", Bone, vol. 48, no. 3, pp. 524-532, 2011. [http://dx.doi.org/10.1016/j.bone.2010.10.178] [PMID: 21056707]

[2] S.J. Roberts, N. van Gastel, G. Carmeliet, and F.P. Luyten, "Uncovering the periosteum for skeletal regeneration: The stem cell that lies beneath", Bone, vol. 70, pp. 10-18, 2015. [http://dx.doi.org/10.1016/j.bone.2014.08.007] [PMID: 25193160]

[3] J.R. Dwek, "The periosteum: what is it, where is it, and what mimics it in its absence?", Skeletal Radiol., vol. 39, no. 4, pp. 319-323, 2010. [http://dx.doi.org/10.1007/s00256-009-0849-9] [PMID: 20049593]

[4] D.W. Hutmacher, and M. Sittinger, "Periosteal cells in bone tissue engineering", Tissue Eng., vol. 9, suppl. Suppl. 1, pp. S45-S64, 2003. [http://dx.doi.org/10.1089/10763270360696978] [PMID: 14511470]

[5] I.Y. Sung, B.C. Park, Y.S. Hah, H.Y. Cho, J.W. Yun, B.W. Park, Y.H. Kang, H.C. Kim, S.C. Hwang, G.J. Rho, U.K. Kim, D.K. Woo, S.H. Oh, and J.H. Byun, "FOXO1 is involved in the effects of cigarette smoke extract on osteoblastic differentiation of cultured human periosteumderived cells", Int. J. Med. Sci., vol. 12, no. 11, pp. 881-890, 2015. [http://dx.doi.org/10.7150/ijms.13172] [PMID: 26640408]

[6] M.D. Ball, I.C. Bonzani, M.J. Bovis, A. Williams, and M.M. Stevens, "Human periosteum is a source of cells for orthopaedic tissue engineering: A pilot study", Clin. Orthop. Relat. Res., vol. 469, no. 11, pp. 3085-3093, 2011. [http://dx.doi.org/10.1007/s11999-011-1895-x] [PMID: 21547415]

[7] C. Colnot, X. Zhang, and M.L. Knothe Tate, "Current insights on the regenerative potential of the periosteum: Molecular, cellular, and endogenous engineering approaches", J. Orthop. Res., vol. 30, no. 12, pp. 1869-1878, 2012. [http://dx.doi.org/10.1002/jor.22181] [PMID: 22778049]

[8] N. van Gastel, S. Torrekens, S.J. Roberts, K. Moermans, J. Schrooten, P. Carmeliet, A. Luttun, F.P. Luyten, and G. Carmeliet, "Engineering vascularized bone: Osteogenic and proangiogenic potential of murine periosteal cells", Stem Cells, vol. 30, no. 11, pp. 2460-2471, 2012. [http://dx.doi.org/10.1002/stem.1210] [PMID: 22911908]

[9] H.K. Kim, I. Oxendine, and N. Kamiya, "High-concentration of BMP2 reduces cell proliferation and increases apoptosis via DKK1 and SOST in human primary periosteal cells", Bone, vol. 54, no. 1, pp. 141-150, 2013. [http://dx.doi.org/10.1016/j.bone.2013.01.031] [PMID: 23360788]

[10] M. Akiyama, H. Nonomura, S.H. Kamil, and R.A. Ignotz, "Periosteal cell pellet culture system: A new technique for bone engineering", Cell Transplant., vol. 15, no. 6, pp. 521-532, 2006. [http://dx.doi.org/10.3727/000000006783981765] [PMID: 17121163]

[11] M. Akiyama, and M. Nakamura, "Bone regeneration and neovascularization processes in a pellet culture system for periosteal cells", Cell Transplant., vol. 18, no. 4, pp. 443-452, 2009. [http://dx.doi.org/10.3727/096368909788809820] [PMID: 19622231]

[12] M. Akiyama, "Identification of UACA, EXOSC9, and TMX2 in bovine periosteal cells by mass spectrometry and immunohistochemistry", Anal. Bioanal. Chem., vol. 406, no. 24, pp. 5805-5813, 2014. [http://dx.doi.org/10.1007/s00216-014-7673-3] [PMID: 24696107]

[13] M. Akiyama, "Association of $\beta$-tubulin, F-box/Leucine-Rich repeat protein 14, and type 1 procollagen C-peptide in bovine periosteal cells", Curr. Tissue Eng., vol. 3, pp. 2-6, 2014. [http://dx.doi.org/10.2174/2211542003666140617000141] 
[14] D.E. Nelson, S.J. Randle, and H. Laman, "Beyond ubiquitination: The atypical functions of Fbxo7 and other F-box proteins", Open Biol., vol. 3, no. 10, p. 130131, 2013. [http://dx.doi.org/10.1098/rsob.130131] [PMID: 24107298]

[15] H. Okabe, S.H. Lee, J. Phuchareon, D.G. Albertson, F. McCormick, and O. Tetsu, "A critical role for FBXW8 and MAPK in cyclin D1 degradation and cancer cell proliferation", PLoS One, vol. 1, p. e128, 2006. [http://dx.doi.org/10.1371/journal.pone.0000128] [PMID: 17205132]

[16] B.B. Chen, and R.K. Mallampalli, "F-box protein substrate recognition: A new insight", Cell Cycle, vol. 12, no. 7, pp. 1009-1010, 2013. [http://dx.doi.org/10.4161/cc.23071] [PMID: 23255120]

[17] Z. Wang, P. Liu, H. Inuzuka, and W. Wei, "Roles of F-box proteins in cancer", Nat. Rev. Cancer, vol. 14, no. 4, pp. 233-247, 2014 [http://dx.doi.org/10.1038/nrc3700] [PMID: 24658274]

[18] W. Zhou, W. Wei, and Y. Sun, "Genetically engineered mouse models for functional studies of SKP1-CUL1-F-box-protein (SCF) E3 ubiquitin ligases", Cell Res., vol. 23, no. 5, pp. 599-619, 2013. [http://dx.doi.org/10.1038/cr.2013.44] [PMID: 23528706]

[19] R.J. Davis, M. Welcker, and B.E. Clurman, "Tumor suppression by the Fbw7 ubiquitin ligase: Mechanisms and opportunities", Cancer Cell, vol. 26 , no. 4 , pp. 455-464, 2014.

[http://dx.doi.org/10.1016/j.ccell.2014.09.013] [PMID: 25314076]

[20] M.H. Chiang, L.F. Chen, and H. Chen, "Ubiquitin-conjugating enzyme UBE2D2 is responsible for FBXW2 (F-box and WD repeat domain containing 2)-mediated human GCM1 (glial cell missing homolog 1) ubiquitination and degradation", Biol. Reprod., vol. 79, no. 5, pp. 914-920, 2008.

[http://dx.doi.org/10.1095/biolreprod.108.071407] [PMID: 18703417]

[21] C.C. Wang, H.F. Lo, S.Y. Lin, and H. Chen, "RACK1 (receptor for activated C-kinase 1) interacts with FBW2 (F-box and WD-repeat domain-containing 2) to up-regulate GCM1 (glial cell missing 1) stability and placental cell migration and invasion", Biochem. J., vol. 453, no. 2, pp. 201-208, 2013.

[http://dx.doi.org/10.1042/BJ20130175] [PMID: 23651062]

[22] Z. Lin, A. Fateh, D.M. Salem, and G. Intini, "Periosteum: Biology and applications in craniofacial bone regeneration", J. Dent. Res., vol. 93, no. 2, pp. 109-116, 2014.

[http://dx.doi.org/10.1177/0022034513506445] [PMID: 24088412]

[23] H.M. Cherry, A.J. Roelofs, T.B. Kurth, and C. De Bari, "In vivo phenotypic characterisation of nucleoside label-retaining cells in mouse periosteum", Eur. Cell. Mater., vol. 27, pp. 185-195, 2014. [http://dx.doi.org/10.22203/eCM.v027a14] [PMID: 24614984]

[24] M. Monjo, S.F. Lamolle, S.P. Lyngstadaas, H.J. Rønold, and J.E. Ellingsen, "In vivo expression of osteogenic markers and bone mineral density at the surface of fluoride-modified titanium implants", Biomaterials, vol. 29, no. 28, pp. 3771-3780, 2008. [http://dx.doi.org/10.1016/j.biomaterials.2008.06.001] [PMID: 18585777]

[25] T.A. Thamamongood, R. Furuya, S. Fukuba, M. Nakamura, N. Suzuki, and A. Hattori, "Expression of osteoblastic and osteoclastic genes during spontaneous regeneration and autotransplantation of goldfish scale: A new tool to study intramembranous bone regeneration", Bone, vol. 50, no. 6, pp. 1240-1249, 2012.

[http://dx.doi.org/10.1016/j.bone.2012.03.021] [PMID: 22484181]

[26] Matrix Science [homepage on the Internet]. Matrix Science Inc, 2014. Available from: www.matrixscience.com

[27] M. Miura, S. Hatakeyama, K. Hattori, and K. Nakayama, "Structure and expression of the gene encoding mouse F-box protein, Fwd2", Genomics, vol. 62, no. 1, pp. 50-58, 1999. [http://dx.doi.org/10.1006/geno.1999.5965] [PMID: 10585767]

[28] C.S. Yang, C. Yu, H.C. Chuang, C.W. Chang, G.D. Chang, T.P. Yao, and H. Chen, "FBW2 targets GCMa to the ubiquitin-proteasome degradation system", J. Biol. Chem., vol. 280, no. 11, pp. 10083-10090, 2005. [http://dx.doi.org/10.1074/jbc.M413986200] [PMID: 15640526]

[29] H. Zheng, Y. Du, Y. Hua, Z. Wu, Y. Yan, and Y. Li, "Essential role of Fbx114 ubiquitin ligase in regulation of vertebrate axis formation through modulating Mkp3 level", Cell Res., vol. 22, no. 5, pp. 936-940, 2012 [http://dx.doi.org/10.1038/cr.2012.37] [PMID: 22410791]

[30] R. Viñas-Castells, M. Beltran, G. Valls, I. Gómez, J.M. García, B. Montserrat-Sentís, J. Baulida, F. Bonilla, A.G. de Herreros, and V.M. Díaz, "The hypoxia-controlled FBXL14 ubiquitin ligase targets SNAIL1 for proteasome degradation", J. Biol. Chem., vol. 285, no. 6, pp. 3794-3805, 2010.

[http://dx.doi.org/10.1074/jbc.M109.065995] [PMID: 19955572]

[31] The Human Protein Atlas [homepage on the Internet]. The Human Atlas project. Available from: www.proteinatlas.org

[32] M. Uhlén, L. Fagerberg, B.M. Hallström, C. Lindskog, P. Oksvold, A. Mardinoglu, Å. Sivertsson, C. Kampf, E. Sjöstedt, A. Asplund, I. Olsson, K. Edlund, E. Lundberg, S. Navani, C.A. Szigyarto, J. Odeberg, D. Djureinovic, J.O. Takanen, S. Hober, T. Alm, P.H. Edqvist, H. Berling, H. Tegel, J. Mulder, J. Rockberg, P. Nilsson, J.M. Schwenk, M. Hamsten, K. von Feilitzen, M. Forsberg, L. Persson, F. Johansson, M. Zwahlen, G. von Heijne, J. Nielsen, and F. Pontén, "Proteomics. Tissue-based map of the human proteome", Science, vol. 347, no. 6220, p. $1260419,2015$. [http://dx.doi.org/10.1126/science.1260419] [PMID: 25613900] 
[33] H. Nakahara, J.E. Dennis, S.P. Bruder, S.E. Haynesworth, D.P. Lennon, and A.I. Caplan, "In vitro differentiation of bone and hypertrophic cartilage from periosteal-derived cells", Exp. Cell Res., vol. 195, no. 2, pp. 492-503, 1991. [http://dx.doi.org/10.1016/0014-4827(91)90401-F] [PMID: 2070830]

\section{C) 2018 Mari Akiyama.}

This is an open access article distributed under the terms of the Creative Commons Attribution 4.0 International Public License (CC-BY 4.0), a copy of which is available at: https://creativecommons.org/licenses/by/4.0/legalcode. This license permits unrestricted use, distribution, and reproduction in any medium, provided the original author and source are credited. 